\title{
BMJ Factors that prolong the 'postmortem Open interval until finding' (PMI-f) among community-dwelling elderly individuals in Japan: analysis of registration data
}

\author{
Tomoko Ito, ${ }^{1,6}$ Nanako Tamiya, ${ }^{1}$ Hideto Takahashi, ${ }^{2}$ Kentaro Yamazaki, ${ }^{3}$ \\ Hideki Yamamoto, ${ }^{4}$ Shoji Sakano, ${ }^{5}$ Masayo Kashiwagi, ${ }^{1}$ Satoru Miyaishi ${ }^{6}$
}

To cite: Ito T, Tamiya N, Takahashi $\mathrm{H}$, et al. Factors that prolong the 'postmortem interval until finding' (PMI-f) among community-dwelling elderly individuals in Japan: analysis of registration data. BMJ Open 2012;2:e001280. doi:10.1136/bmjopen-2012001280

- Prepublication history and additional material for this paper are available online. To view these files please visit the journal online (dx.doi.org/10.1136/ bmjopen-2012-001280).

Received 14 June 2012 Accepted 28 August 2012

This final article is available for use under the terms of the Creative Commons Attribution Non-Commercial 2.0 Licence; see http://bmjopen.bmj.com

For numbered affiliations see end of article.

Correspondence to Dr Nanako Tamiya; ntamiya@md.tsukuba.ac.jp

\section{ABSTRACT}

Objectives: To clarify the factors affecting 'postmortem interval until finding' (PMI-f) among elderly unexpected death cases.

Design: Cross-sectional study.

Setting: All area of Yamagata prefecture in Japan. Participants: Entering subjects were 5675 elderly cases with age of $\geq 65$ years selected from all 9002 cases of unexpected death from 2002 to 2007 in Yamagata prefecture between 2002 and 2007. Our final study subjects consisted of 3387 cases sampled with several criteria to assess the factors to prolong PMI-f.

Primary outcome measures: The outcome was the postmortem interval until finding (PMI-f) as the time from death until finding the body which we defined in this study.

Results: 'Living alone' showed the highest adjusted HR $(3.73,95 \% \mathrm{Cl} 3.37$ to 4.13$)$, also 'unnatural death' $(1.50,1.28$ to 1.75$)$, 'found at own home' $(1.37,1.22$ to 1.55$)$ and 'younger subjects' $(0.99,0.98$ to 0.99$)$. In the model including interactions with the household situation, we found 'male subjects living alone' and 'female subjects living with family' tended to be found later.

Conclusions: PMI-f is an effective outcome for quantitative analyses of risk of bodies left. To prevent the elderly dead bodies left for long time, it is necessary to keep regular home-based contact with elderly individuals living alone.

\section{INTRODUCTION}

In Japan, the population has been ageing at the highest rate in the developed world, and the proportion of people 65 and older was $23 \%$ in 2010. It has been projected that about $30 \%$ of the total population will be older than 65 in $2050 .{ }^{1}$ The low total fertility rate, 1.37 in 2009 , is also adding to the rapid changes in the Japanese population structure. In

\section{ARTICLE SUMMARY}

Article focus

- Elderly Solitary Death, the case of elderly dead body left for long time and having regrettable postmortem body change, is the public health issue in ageing society. We tried to reveal the causal relation for the dead bodies left for long time.

Key messages

- Our results showed who, how, and how long a time elderly individuals' bodies tend not to be found. This study should help policy makers to identify and counsel of citizens at risk and to assess priorities for their services given limited budgets.

Strengths and limitations of this study

- Our data were based on only one region. However, no study has discussed the causal factors involved in the dead bodies left for long time using the huge data of forensic medicine through several years.

addition to this rapid ageing, dramatic changes in family situations have occurred, affecting several aspects of society and leading to the weakening of the caretaking function traditionally performed by families.

At the same time, solitary death among elderly individuals has appeared as a new social problem related to the ageing society. The phrase 'solitary death' came into use in the mass media's reporting of a case that occurred in Japan during the 1980s in which the skeletal remains of an elderly person living alone was found as a result of the prolonged length of time from death until the finding of the dead body. ${ }^{2}$ The Japanese people were shocked by the individual's remarkable postmortem bodily changes. 
Cleaning solitary deaths up has been established as a business for stable incidents of elderly solitary deaths. That unusual job was noticed by foreigners and elderly solitary death was introduced as just a Japanese problem. ${ }^{3}$ However, this Japanese issue has been spread over the sea. In Korea, several solitary deaths were reported in $2011 .{ }^{4}$ Korean rapid ageing of society with similarity to Japan has also influenced the social function around family.

However, what is 'solitary death' has not been defined clearly yet. Most of articles, which had tried to reveal the 'solitary death,' mentioned that this lack of definition is the biggest problem. One letter article from Japan showed the 35 cases treated as solitary deaths in 8 years from 2000. They showed the association between incident of solitary death and person who found resident's status in the public housing complex. ${ }^{5}$ In this report, they defined whether a case is solitary death or not depending on subjective opinion of person who found the case. One study operationally defined solitary death as unexpected death among the people living alone,${ }^{6}$ in the other study, they added the death occurred at their own house on that definition. ${ }^{7}$ As a broader definition, there were some articles said solitary death is occurred not only among people living alone. ${ }^{8}$ One study researched the municipal bodies' practices for solitary death. ${ }^{10}$ They revealed that the definition of solitary death was varied.

Under these confused background, many studies tried to explain solitary death with various view points, such as household, ${ }^{6-8}{ }^{10-12}$ age of subject, ${ }^{6}{ }^{7} 10^{11}$ cause of death, ${ }^{781011}$ the place where the subject was found, ${ }^{810}$ or the person who found the subject. ${ }^{7812}$ All of these articles dealt with the time spent after the death ${ }^{6-8}{ }^{10-12}$ as main characteristic of solitary death. The death left for long time and making remarkable postmortem bodily change must be avoided and the time spent after the death can be an important view point on solitary death. Therefore, in this study, we focused solely on this time spent after the death and analysed the factors affected on it.

About the time spent after the death, the 'postmortem interval' (PMI) is the essential parameter in forensic medicine. PMI is defined as the time from death until examination. There is one study on this PMI and they showed that the average of PMI was longer among the elderly living alone. ${ }^{6}$ However, because our study focused on the finding of a dead body, we defined the 'PMI until finding' (PMI-f) as the period from the estimated time of death until the finding of the dead body.

To obtain information about PMI-f, we focused on forensic medical data. Forensic medical data, especially the postmortem examination (inspection) records, are informative in understanding the circumstances of deaths, including those involving elderly cases with long PMI-f.

On this PMI-f from forensic data, one study has been published. This study treated PMI-f as a categorical variable and presented only descriptive findings. ${ }^{7}$ To our knowledge, no study has discussed the causal factors to prolong the finding of the dead body and has analysed
PMI-f as a continuous quantity with Cox regression model. In addition, the household situation has been considered to be the prior factor making the differences in the process of leaving and finding of the dead body according to the literatures reported previously. ${ }^{6} 813$ Thus, the aim of the present study was to clarify the factors affecting PMI-f among elderly unexpected death cases by elderly people, focusing on the affect by the household situation.

\section{METHODS}

\section{Definition of PMI- $f$}

We defined the PMI-f as the time from death until finding the body. Thus, PMI-f typically has a positive value. Occasionally, the body is found earlier than the estimated time of death such as when a person is found dying and is rushed to the emergency unit of a hospital. In these cases, the death was confirmed by a medical doctor after medical examination.

\section{Study setting}

The subjects, which were registered in Yamagata prefectural police headquarter in Japan, consisted of 9002 cases of unexpected death from 2002 to 2007; they were a subset of the total of 76788 deaths in Yamagata prefecture between 2002 and 2007.

In Japan, police officers investigate all reported unexpected deaths to determine whether it is criminal case or not. Japanese law mandates that doctors report all unexpected deaths to the police. Even subjects whose death is witnessed (eg, when individuals are rushed to a hospital) are also subject to postmortem examination ifthe situations are not clear. If necessary, the autopsy is conducted as further examination by forensic pathologist.

Consent for use of the data was approved by Yamagata prefectural police headquarter after a formal application and explicit pledge to randomise all data and remove any individual identifiers to protect the privacy of the personal data supplied. Ethical considerations were examined in accordance with Japanese epidemiological guidelines for secondary data analysis. Our study was approved by the official ethical review board of University of Tsukuba and Yamagata University.

We used the following six criteria for selecting subjects in that order shown in figure 1 .

1. Age of $\geq 65$ years $(n=5,675)$ were included.

2. The subject whose PMI-f was zero or positive was included. Eight subjects were excluded because of missing data about the death or time of finding the body, and 1386 subjects were excluded because their PMI-f was less than zero.

3. Unclear cause of death $(n=133)$ were excluded.

4. The cases involving suicide $(n=606)$ and homicide $(n=14)$ were excluded because the PMI-f was influenced by human intentions or actions and these cases could not meet the situation of solitary death.

5. Accidental fire $(n=27)$ were excluded. Notification of the accident and PMI-f tended to be much shorter in 
Figure 1 Sampling for final subjects.

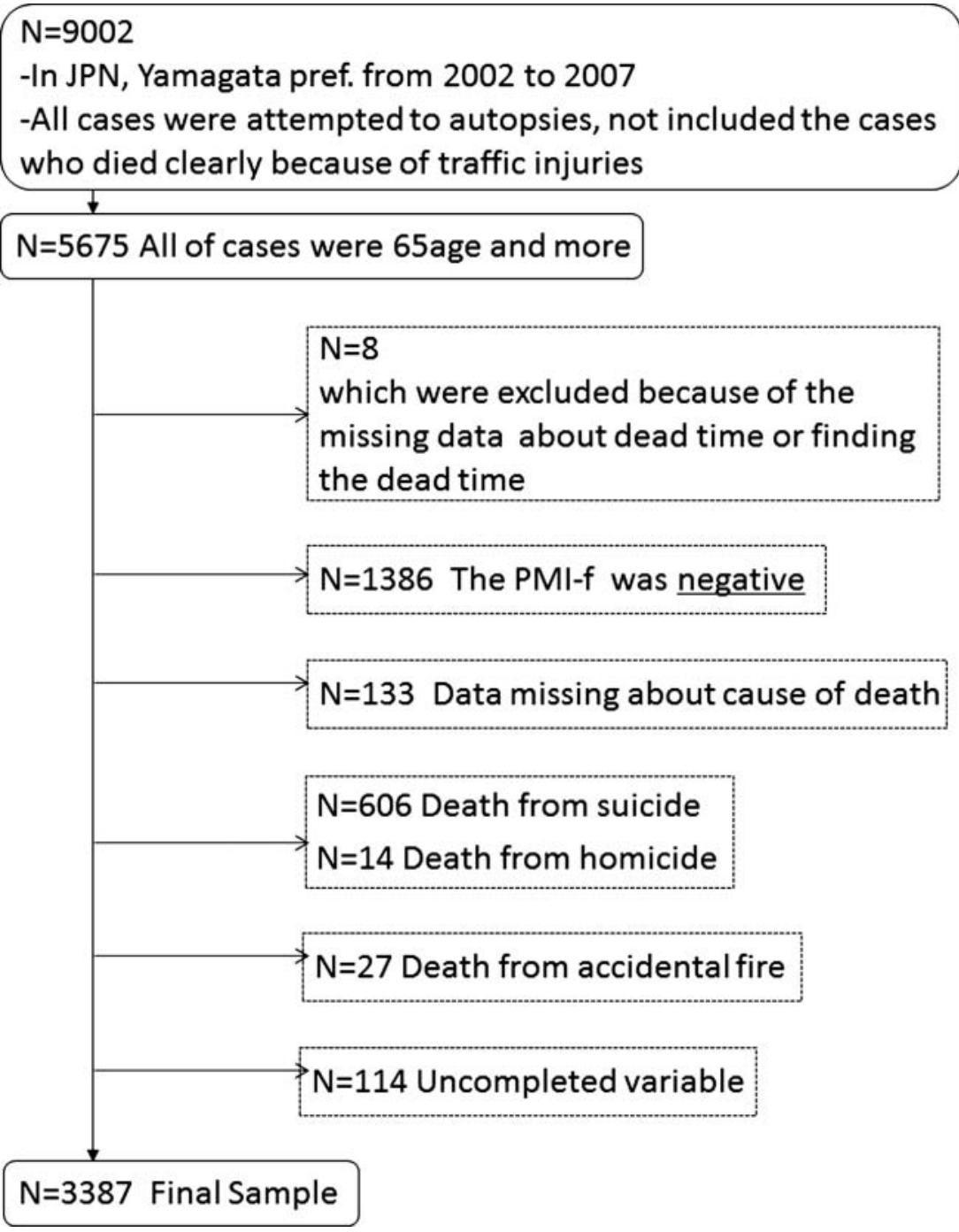

cases of accidental fire than in other accidental deaths because of the resulting fire and smoke. ${ }^{8}$

6. Availability of complete data regarding the variables in our analytical model; 114 subjects were excluded because of incomplete data.

\section{Variables}

We used data about the following characteristics of the subjects; age at death, sex and household situation. In the autopsy, the police officers make the inquiry about subjects' living situation into subjects' relatives, neighbourhoods or any persons concerned, and make the official records of autopsy. The cause of death was classified as the natural death or the unnatural death from accident. We also analysed data about the relationship between the subjects and the person who found them and the place at which they were found.

\section{Statistical analyses}

First, we summarised the characteristics of the subjects in terms of exact numbers and proportions (table 1).
Second, we prepared Kaplan-Meier estimates with the generalised Wilcoxon test between the two categories of sex, household situation, cause of death, the place at which the subject was found, and the person who found the subject (results not shown). All the explanatory variables except for age were treated as dichotomous for purposes of simplicity. A Cox regression was conducted to establish the factors that prolonged the PMI-f with adjusting for the explanatory variables. We checked proportionality in the Cox model by the linearity of the $\log -\log$ plot of the variables.

To assess the affect by the household situation, we created the product terms of the household situation to estimate the influence of interactions and analysed the models stratified by the household situation.

We used a significance level of 0.05 throughout this study. All analyses were conducted using the SAS software (V.9.1; SAS Institute Inc, Cary, North Carolina, USA).

\section{RESULTS}

Our final study sample consisted of 3387 cases. Characteristics of the study sample are presented in 
Table 1 Characteristics and situations in which study subject died and was found

\begin{tabular}{|c|c|}
\hline Variables & n (\%) \\
\hline \multicolumn{2}{|l|}{ Age } \\
\hline $65 \leq,<75$ & 957 (28.3) \\
\hline $75 \leq,<85$ & $1565(46.2)$ \\
\hline $85 \leq$ & $865(25.5)$ \\
\hline \multicolumn{2}{|l|}{ Sex } \\
\hline Male & $1892(55.9)$ \\
\hline Female & $1495(54.1)$ \\
\hline \multicolumn{2}{|l|}{ Household situation } \\
\hline Living alone & 659 (19.5) \\
\hline Living with family & $2728(80.5)$ \\
\hline \multicolumn{2}{|c|}{ Variables related to how study subject died } \\
\hline \multicolumn{2}{|c|}{ Cause of death } \\
\hline Natural death & $3143(92.8)$ \\
\hline Cardiac problems & $2390(76.0)$ \\
\hline Brain hemorrhage & 441 (14.0) \\
\hline Others & $312(9.9)$ \\
\hline Unnatural death & $244(7.2)$ \\
\hline Drowning & $70(28.7)$ \\
\hline Falling from a height & $61(25.0)$ \\
\hline Suffocation & $57(23.4)$ \\
\hline Hypothermia & $20(8.2)$ \\
\hline Poisoning & $3(1.2)$ \\
\hline Others & $33(13.5)$ \\
\hline \multicolumn{2}{|c|}{ Place at which the subject was found } \\
\hline Indoors & $3073(90.7)$ \\
\hline At own home site & 2766 (90.0) \\
\hline In hospital & $224(7.3)$ \\
\hline At hotel & $55(1.8)$ \\
\hline At relative's home & $7(0.2)$ \\
\hline In vehicle at own home & $2(0.0)$ \\
\hline In hut in mountain or forest & $1(0.0)$ \\
\hline Others & $18(0.6)$ \\
\hline Outdoors & $314(9.3)$ \\
\hline In water* & $100(31.8)$ \\
\hline On own property & $63(20.1)$ \\
\hline In mountain or forest & $44(14.0)$ \\
\hline On street & $26(8.3)$ \\
\hline In vehicle on street & $13(4.1)$ \\
\hline In hospital & $2(0.6)$ \\
\hline At relative's home & $3(1.0)$ \\
\hline Others & $63(20.1)$ \\
\hline \multicolumn{2}{|l|}{ Person who found the subject } \\
\hline Not family member & $803(23.7)$ \\
\hline Neighbour & 176 (21.9) \\
\hline Passer-by & $90(11.2)$ \\
\hline Others & 537 (66.9) \\
\hline Family member & $2584(76.3)$ \\
\hline All & 3387 \\
\hline
\end{tabular}

${ }^{*}$ In a river, pond, lake, body of water used for industrial or agricultural purposes or a reservoir.

table 1 . Over $70 \%$ of all cases were older than 75 years of age, and the maximum age was 101. In 659 cases (20\%), the subject lived alone. Most dead bodies were found by family members $(76 \%)$. The distribution of PMI-f is shown in table 2. The maximum PMI-f was 365 days. This was the one case which was older than 75 , female, natural death and found at own home by her family member. The PMI-f in 96 cases $(3 \%)$ was zero. The distribution of PMI-f was concentrated around less than 1 day $(87 \%)$. Among $49 \%$ of subjects living alone, their PMI-fs were more than 1 day.

Crude and adjusted HRs and 95\% CIs for increasing of PMI-f were shown in table 2. In the crude models, the four variables with significant HRs were age, household situation, the place at which the dead body was found, and the person who found the dead body. The adjusted risk of living alone was the highest of all independent variables (HR 3.73, 95\% CI 3.37 to 4.13 ). In the adjusted model, younger age $(0.99,0.98$ to 0.99$)$, unnatural death due to an accident $(1.50,1.28$ to 1.75$)$ and found at one's own home $(1.37,1.22$ to 1.55$)$ were also significant risk factors that delayed the finding of bodies.

The results of the model including interactions are also shown in table 2. Living alone showed the strongest influence $(2.34,1.64$ to 3.33$)$ also in the fully adjusted model including interactions. Other variables related to long PMI-f: age $(0.99,0.98$ to 0.99$)$, male $(0.89,0.82$ to $0.96)$, unnatural death $(1.45,1.24$ to 1.72$)$ and finding at own home (1.32, 1.14 to 1.52$)$. Significant interactions of the household situation (=living alone) were observed among male (1.31, 1.10 to 1.56$)$ and finding at one's own home (1.47, 1.06 to 2.05 ).

The HRs of the multivariate model with interactions, 0.89 for sex, 2.34 for household situation and 1.34 for their interaction, mean that the males of living alone prolong the median PM-f 0.92 day, the males with family shrink it 0.01 day, and the females of living alone prolong it 0.29 day, with the reference of the females with family, which are obtained by transforming these HRs to median PM-f days in the model (not shown in table). The stratified analysis in table 3 showed the significant relations with longer PMI-f, among subjects living alone, finding at own home $(1.99,1.48$ to 2.67$)$, unnatural death $(1.72,1.02$ to 2.91$)$, male $(1.23,1.04$ to $1.44)$, younger age $(0.97,0.96$ to 0.98$)$ in the adjusted model shown in table 3. Among subjects living with family, sex of male related shorter PMI-f $(0.92,0.85$ to 0.99 ) as opposed to the case in living alone.

\section{DISCUSSION}

We assessed the factors affecting PMI-f using Cox regression models on forensic medical data. These results showed that living alone was the single most influential factor contributing to delays in finding elderly dead body. Other factors included death attributable to external causes, and younger age. We also considered interactions between household situation and other the independent variables, and found additional effects on delays in finding the dead body. These interactions may be interpreted in a multicausal model and our model referred to more empirical conclusion. To our knowledge, this is the first published study to conduct 


\begin{tabular}{|c|c|c|c|c|c|c|c|c|c|c|c|}
\hline \multirow[b]{2}{*}{ Variables } & \multirow[b]{2}{*}{$n$} & \multicolumn{4}{|c|}{ PMI-f (days) } & \multicolumn{2}{|c|}{ Univariate models } & \multicolumn{2}{|c|}{ Multivariate model } & \multicolumn{2}{|c|}{$\begin{array}{l}\text { Multivariate model } \\
\text { with interactions }\end{array}$} \\
\hline & & Median & IQR & Q1 & Q3 & HR & $95 \% \mathrm{Cl}$ & HR† & 95\% Cl† & HR‡ & 95\% Cl¥ \\
\hline Age & & & & & & 0.98 & 0.97 to 0.98 & 0.99 & 0.98 to 0.99 & 0.99 & 0.98 to 0.99 \\
\hline $65 \leq,<75$ & 957 & 0.17 & 0.57 & 0.03 & 0.60 & & & & & & \\
\hline $75 \leq,<85$ & 1565 & 0.13 & 0.40 & 0.02 & 0.42 & & & & & & \\
\hline $85 \leq$ & 865 & 0.10 & 0.26 & 0.02 & 0.28 & & & & & & \\
\hline \multicolumn{12}{|l|}{ Sex } \\
\hline Male & 1892 & 0.12 & 0.36 & 0.02 & 0.38 & 0.96 & 0.90 to 1.03 & 0.93 & 0.87 to $1.00^{*}$ & 0.89 & 0.82 to 0.96 \\
\hline Female & 1495 & 0.15 & 0.41 & 0.03 & 0.44 & 1.00 & & 1.00 & & 1.00 & \\
\hline \multicolumn{12}{|l|}{ Household situation } \\
\hline Living alone & 659 & 1.00 & 2.54 & 0.46 & 3.00 & 3.92 & 3.58 to 4.31 & 3.73 & 3.37 to 4.13 & 2.34 & 1.64 to 3.33 \\
\hline Living with family & 2728 & 0.08 & 0.23 & 0.01 & 0.24 & 0.24 & & 1.00 & & 1.00 & \\
\hline \multicolumn{12}{|l|}{ Cause of death } \\
\hline Unnatural death & 244 & 0.07 & 0.40 & 0.00 & 0.40 & 0.89 & 0.78 to 1.02 & 1.50 & 1.28 to 1.75 & 1.46 & 1.24 to 1.72 \\
\hline Natural death & 3143 & 0.13 & 0.37 & 0.03 & 0.40 & 1.00 & & 1.00 & & 1.00 & \\
\hline \multicolumn{12}{|l|}{ Place at which the subject was found } \\
\hline At own home & 2766 & 0.16 & 0.40 & 0.04 & 0.44 & 1.53 & 1.40 to 1.67 & 1.37 & 1.22 to 1.55 & 1.32 & 1.14 to 1.52 \\
\hline Not at own home & 621 & 0.03 & 0.23 & 0.00 & 0.23 & 1.00 & & 1.00 & & 1.00 & \\
\hline \multicolumn{12}{|l|}{ Person who found the subject } \\
\hline Not family member & 803 & 0.19 & 0.98 & 0.00 & 0.98 & 1.40 & 1.29 to 1.52 & 1.02 & 0.92 to 1.13 & 1.04 & 0.90 to 1.19 \\
\hline Family member & 2584 & 0.13 & 0.29 & 0.03 & 0.32 & 1.00 & & 1.00 & & 1.00 & \\
\hline \multicolumn{12}{|l|}{ (interaction terms§) } \\
\hline Living alone and male & & & & & & & & & & 1.31 & 1.10 to 1.56 \\
\hline Living alone and unnatural death & & & & & & & & & & 1.12 & 0.64 to 1.96 \\
\hline Living alone and finding at own home & & & & & & & & & & 1.47 & 1.06 to 2.05 \\
\hline Living alone and not finding by family member & & & & & & & & & & 0.93 & 0.75 to 1.14 \\
\hline
\end{tabular}


Table 3 Distribution of postmortem interval until finding (PMI-f) and HRs stratified by household situation

\begin{tabular}{|c|c|c|c|c|c|c|c|c|c|}
\hline \multirow[b]{2}{*}{ Variables } & \multirow[b]{2}{*}{$n$} & \multicolumn{4}{|c|}{ PMI-f (day) } & \multicolumn{2}{|c|}{ Univariate models } & \multicolumn{2}{|c|}{ Multivariate model } \\
\hline & & Median & IQR & Q1 & Q3 & HR & $95 \% \mathrm{Cl}$ & HR† & 95\% Cl† \\
\hline \multicolumn{10}{|l|}{ Living alone $(n=659)$} \\
\hline Age & & & & & & 0.97 & 0.96 to 0.98 & 0.97 & 0.96 to 0.98 \\
\hline $65 \leq,<75$ & 245 & 1.61 & 3.30 & 0.53 & 3.83 & & & & \\
\hline $75 \leq,<85$ & 315 & 0.99 & 2.56 & 0.44 & 3.00 & & & & \\
\hline $85 \leq$ & 99 & 0.61 & 1.44 & 0.36 & 1.80 & & & & \\
\hline \multicolumn{10}{|l|}{ Sex } \\
\hline Male & 343 & 1.19 & 2.81 & 0.46 & 3.27 & 1.29 & 1.11 to 1.51 & 1.23 & 1.04 to 1.44 \\
\hline Female & 316 & 0.87 & 1.56 & 0.46 & 2.02 & 1.00 & & 1.00 & \\
\hline \multicolumn{10}{|l|}{ Cause of death } \\
\hline Unnatural death & 17 & 1.61 & 2.03 & 0.45 & 2.48 & 1.00 & 0.62 to 1.61 & 1.72 & 1.02 to 2.91 \\
\hline Natural death & 642 & 1.00 & 2.54 & 0.46 & 3.00 & 1.00 & & 1.00 & \\
\hline \multicolumn{10}{|c|}{ Place at which the subject was found } \\
\hline At own home & 600 & 1.08 & 2.50 & 0.50 & 3.00 & 1.74 & 1.33 to 2.28 & 1.99 & 1.48 to 2.67 \\
\hline Not at own home & 59 & 0.27 & 1.94 & 0.00 & 1.94 & 1.00 & & 1.00 & \\
\hline \multicolumn{10}{|c|}{ Person who found the subject } \\
\hline Not family member & 337 & 0.98 & 2.54 & 0.46 & 3.00 & 0.95 & 0.82 to 1.11 & 0.94 & 0.82 to 1.08 \\
\hline Family member & 322 & 1.08 & 2.54 & 0.46 & 3.00 & 1.00 & & 1.00 & \\
\hline \multicolumn{10}{|c|}{ Living with family ( $\mathrm{n}=2728)$} \\
\hline Age & & & & & & 0.99 & 0.99 to $1.00^{*}$ & 0.99 & 0.99 to $1.00^{*}$ \\
\hline $65 \leq,<75$ & 712 & 0.08 & 0.24 & 0.01 & 0.25 & & & & \\
\hline $75 \leq,<85$ & 1250 & 0.08 & 0.23 & 0.01 & 0.24 & & & & \\
\hline $85 \leq$ & 766 & 0.08 & 0.19 & 0.02 & 0.21 & & & & \\
\hline \multicolumn{10}{|l|}{ Sex } \\
\hline Male & 1549 & 0.08 & 0.22 & 0.01 & 0.23 & 0.93 & 0.86 to $1.00^{*}$ & 0.92 & 0.85 to 0.99 \\
\hline Female & 1179 & 0.09 & 0.22 & 0.02 & 0.24 & 1.00 & & 1.00 & \\
\hline \multicolumn{10}{|l|}{ Cause of death } \\
\hline Unnatural death & 227 & 0.06 & 0.33 & 0.00 & 0.33 & 1.17 & 1.02 to 1.35 & 1.35 & 1.02 to 2.91 \\
\hline Natural death & 2501 & 0.08 & 0.21 & 0.02 & 0.23 & 1.00 & & 1.00 & \\
\hline \multicolumn{10}{|c|}{ Place at which the subject was found } \\
\hline At own home & 2166 & 0.10 & 0.21 & 0.03 & 0.24 & 1.17 & 1.06 to 1.28 & 1.32 & 1.14 to 1.51 \\
\hline Not at own home & 562 & 0.02 & 0.20 & 0.00 & 0.20 & 1.00 & & 1.00 & \\
\hline \multicolumn{10}{|c|}{ Person who found the subject } \\
\hline Not family member & 466 & 0.01 & 0.19 & 0.00 & 0.19 & 0.87 & 0.79 to 0.97 & 0.94 & 0.82 to 1.08 \\
\hline Family member & 2262 & 0.10 & 0.21 & 0.03 & 0.24 & 1.00 & & 1.00 & \\
\hline
\end{tabular}

${ }^{*} \mathrm{p}<0.05$.

†Age, sex, person who found the subject, cause of death and place at which the subject was found.

statistical analyses with estimated models to reveal factors related to PMI 'until finding.'

The analyses demonstrated that living alone was the strongest predictor of delays in finding elderly dead bodies; the risk was about four times higher in this group than in those living with family. This finding suggests that elderly subjects living alone were isolated and contactless. One study surveyed survival after falling among people living alone in San Francisco. ${ }^{13}$ Of 387 people, 90 were left un-rescued for an average of $18 \mathrm{~h}$ after becoming helpless in their own homes and died. Citizens living alone were difficult to find if they fell down. In Japan, the proportion of community-dwelling elderly individuals living alone is increasing with ageing. The proportion of elderly individuals living alone among whole elderly people was $13.8 \%$ in 2000 and $16.4 \%$ in $2010 .{ }^{14}$ This high risk to left the dead body for long time in living alone became an urgent public health issue.
We found the contrary results regarding sex between household situations (living alone or with family). 'Male subjects living alone' and 'female subjects living with family' tended to prolong their PMI-f. Male elderly people, in general, are said to have poor social relation. Thus, their dead bodies should be difficult to be found by their neighbourhoods or friends. However, among the subjects living with family, male subjects tend to be found their dead bodies than female subjects. In cases of male people, their family member will make more effort to seek. This might be due to the presence of souse. In Japan, the life expectancy is longer in female people than in male ${ }^{15}$ and the age of a husband used to be older than his wife. ${ }^{15}{ }^{16}$ It is suggested that the number of female widows were greater than male.

Interaction between living alone and dying at one's own home showed effect on PMI-f. This interaction showed the situation that elderly individual's home could be a risk factor to make them more isolated. This risk 
indicates the need for automatic alarm-and-notification systems. Some municipalities provide such systems connected to local rescue services. ${ }^{17}$ If accidents occur, the systems can notify to rescue services. In addition to these systems, an important first step in preventing solitary death is to raise public awareness of the likelihood that elderly people living alone may become helpless and isolated in their homes within a community.

Regarding the causes of death included in our model, unnatural causes (eg, drowning, suffocation and falling) were associated with the fact that they are found later. It is natural that the people who were under medical care with some internal diseases can be found earlier. In contrast, external accidents happen suddenly, and therefore it is difficult for relatives to find the dead bodies. In really, the biggest single cause of incapacitation that was left alone was reported to be a fall. ${ }^{13}$

In our adjusted model, younger individuals' deaths were found later. This suggests that accidents may have had a bigger impact on younger elderly than older individuals because the former may have been less concerned about death. The situation in which an individual dies and her/his dead body is found can be affected by her/his life and relationships while alive, especially in cases of unfortunate accidents. With a little of individual's concern and correspondence about her/ his possibility of death, the people around her/him also can less take care of her/him death and find the dead body later.

We found differences between the crude and adjusted models with regard to significant variables. The identity of the person who found the dead body did not affect the PMI-f in the adjusted model. This indicates that who found the dead body depended on other factors and so that there was no directive this variable's association to PMI-f.

Our present study had several limitations. Variable settings were based on the official record written about the living and dying among the subjects by police officers. Variables including basic characteristics and other components were confirmed to be recorded. Those records were based on the inquires by the police office; however, the accuracy of the information was not secured and it is difficult to assess the validation retrospectively. All of our study subjects were the cases that were reported as unexpected deaths and that were examined by police officers. This reporting system abides by law with compulsion for medical doctors. However, there should be unexpected deaths that are not reported and not performed autopsies. For example, if the doctors have known the family and attended the elderly before, they may not report the unexpected death. If such underreported cases were present, our PMI-f should be longer than actual one because PMI-f in such cases may not be so long. Other situations also may present. Our results should be captured under this limitation.

The PMI-f was analysed as an outcome in our multivariate model for the first time. Our results showed who, how, and how long a time elderly individuals' bodies tend not to be found. These findings can provide the basis for more effective measures to prevent the phenomena of solitary death among elderly individuals; the delays in finding the bodies of elderly individuals that lead to regrettable postmortem changes. This study should help policy makers to identify and counsel of citizens at risk and to assess priorities for their services given limited budgets. Future studies should evaluate interventions designed to prevent solitary death among elderly individuals and this PMI-f could be a useful quantitative indicator.

\section{Author affiliations}

${ }^{1}$ Department of Health Services Research, Doctoral Program in Human Care Science, Graduate School of Comprehensive Human Sciences, University of Tsukuba, Tsukuba, Japan

${ }^{2}$ Department of Epidemiology and Biostatistics, School of Medicine, University of Tsukuba, Tsukuba, Japan

${ }^{3}$ Department of Forensic Medicine, Yamagata University, Yamagata, Japan

${ }^{4}$ School of Public Health, Teikyo University, Tokyo, Japan

${ }^{5}$ Suginami Public Health Center, Tokyo Metropolitan Government, Tokyo, Japan

${ }^{6}$ Department of Legal Medicine, Graduate School of Medicine, Dentistry and Pharmaceutical Sciences, Okayama University, Okayama, Japan

Acknowledgements We thank the members of the Health Service Research Laboratory at the University of Tsukuba, Dr Nishi in Harvard University and Dr Kakiuchi in Yokohama City University, whose comments and suggestions were of great value in our study.

Contributors All authors conceived the protocol of this study, especially KY contributed in data collections, SS gave advices from the viewpoint of governments and SM coordinated our study group. TI and NT performed the study and analyses the data together with biostatistician HT. TI, NT, HT, KY, $\mathrm{HY}$ and SM co-wrote the paper. All authors discussed the results and commented on the manuscript.

Funding This work was supported by MEXT KAKENHI (24249031): Grant-in-Aid for Scientific Research (A) and by Health Labour Sciences Research Grant.

Competing interests None.

Ethics approval Ethical board in University of Tsukuba.

Provenance and peer review Not commissioned; externally peer reviewed.

Data sharing statement Data use was restricted within the study group and so is not available.

\section{REFERENCES}

1. Ministry of Health, Labor and Welfare. Annual Health, Labor and Welfare Report Part 1 "Supports for Independence in Order to Stabilize Living and Society." http://www.mhlw.go.jp/za/0825/c04/ c04.html (accessed 31 Mar 2011). (in Japanese)

2. Nakazawa T, Shukutoku University solitary-death research group. Apartments and solitary death. Tokyo: Chuohoki Publishing, 2008. (in Japanese)

3. Nobel J. Japan's 'Lonely Deaths': A business opportunity. Tokyo: Time Inc., 2010

4. Kim K. Lonely life, solitary death. Seoul: Korean Herald, 2011.

5. Fukukawa Y. Solitary death: a new problem of an aging society in Japan. J Am Geriatr Soc 2011;59:2.

6. Kanewaku M, Mori S, Abe N, et al. Unexpected death statistics according to classification of households: survey of solitary-death statistics in the Tokyo metropolitan area. $J$ Health Welf Stat 2010;57:20-5. (in Japanese)

7. Osawa M. The realities of solitary death in Yamagata Prefecture. Jpn Med Assoc Mag Police 2006;1:34-7. (in Japanese) 
8. Matsuzawa A, Tamiya $\mathrm{N}$, Yamamoto $\mathrm{H}$, et al. The realities and background factors of senior citizen deaths in autopsy cases of so-called solitary-deaths. J Health Wel Stat 2009;56:1-7. (in Japanese)

9. NHK special crewSasaki T. Alone, dying with nobody-a sudden increasing of solitary death and preventions. Tokyo: Hankyu Communications Co., Ltd. 2007. (in Japanese)

10. Fukukawa Y, Kawaguchi K. A nationwide survey of Japanese municipalities on solitary deaths and countermeasures. Nihon Koshu Eisei Zasshi 2011;58:959-66. (in Japanese)

11. Fukunaga T, Abe N, Tanifuji T. Sudden death and solitary death in aged individuals. Jpn J Acute Med 2005;29:1873-7. (in Japanese)

12. Yamazaki K, Tamiya N, Matsuzawa A, et al. Epidemiological study of "solitary deaths" and regional differences between Yamagata prefecture and Tokyo metropolitan area. Houigaku no Jissai to Kenkyu 2009;52:227-35. (in Japanese)
13. Gurley RJ, Lum N, Sande M, et al. Persons found in their homes helpless or dead. N Engl J Med 1996;334:1710-16.

14. Ministry of Health Labour and Welfare. Japan censuses result in 2010. The basic statistics 2011. http://www.stat.go.jp/data/kokusei/ 2010/kihon1/pdf/gaiyou1.pdf. (accessed 26 Jan 2012).

15. Ministry of Health Labour and Welfare. Population, Live births, Deaths, Infant deaths, Neonatal deaths, Natural change, Foeta deaths, Perinatal deaths, Marriages, Divorces. Summary of Vital Statistics 2012. http://www.mhlw.go.jp/english/database/db-hw/ populate/dl/01.pdf. (accessed 9 Aug 2012).

16. Tamiya N. Gender issues in elderly care and possible solutions. Nippon Ronen Igakkai Zasshi 2008;45:4. (in Japanese)

17. Ministry of Health, Labor and Welfare. Conference Report about the Promotion of Elderly Community-making (Aimed at "Zero Solitary Deaths") and the ability to live alone with relief. http://www.mhlw.go.jp/ houdou/2008/03/h0328-8.html. (accessed 31 Mar 2011). (in Japanese) 